\title{
Marcin Lewiński
}

Universidade Nova de Lisboa

\section{ARGUMENTATIVE POLYLOGUES: BEYOND DIALECTICAL UNDERSTANDING OF FALLACIES}

\begin{abstract}
Dialectical fallacies are typically defined as breaches of the rules of a regulated discussion between two participants (di-logue). What if discussions become more complex and involve multiple parties with distinct positions to argue for (poly-logues)? Are there distinct argumentation norms of polylogues? If so, can their violations be conceptualized as polylogical fallacies? I will argue for such an approach and analyze two candidates for argumentative breaches of multi-party rationality: false dilemma and collateral straw man.
\end{abstract}

Keywords: argumentation, dialectic, fallacies, false dilemma, polylogue, straw man

\section{Introduction}

The argument of this paper proceeds as follows:

The chief goal of normative theories of argumentation is to define (a system of) correct argumentation and thus, a contrario, define fallacies: incorrect argumentations that happen but should not. Among various possibilities, argumentative correctness can be co-defined with "intelligent interaction" (van Benthem, 2009, p. vii). An interaction is "intelligent" (rational, reasonable, critical) as long as it is governed by some idealized rules defined in a given model of interaction (or dialogue). For instance, the rules of dialectical models can guarantee that argumentative dialogues have a high error-correcting potential; ideally, errors are mutually eliminated through argumentative moves of the agonistically-minded discussants. Argumentation is incorrect (fallacious) to the extent it violates such rules. Further, an intelligent or rational interaction is, arguably, a species of the genus interaction. But what is interaction? Typically, for the purposes of argumentation theory, it is a dialogue in which two adversaries 


\section{Marcin Lewiński}

(proponent-opponent) argue on both sides of a contested issue, "in accordance with a set of rules or conventions" (Hamblin, 1970, p. 255). Such di-logues, however, do not exhaust the genus interaction. Discourse analysts recognize many other species - tri-logues, tetra-logues, etc.; for short: polylogues - that generate distinctive "rules or conventions." If di-logues are not identical with poly-logues, then, supposedly, an intelligent di-logue is not identical with an intelligent poly-logue. So is there the possibility of, indeed a need for, capturing the rationality of such poly-logical interactions? That would bring to its logical consequence the idea of tying argumentative correctness (and fallaciousness) with norms of intelligent interactions. I argue here for a "yes" answer in three basic steps: 1) I define the concept of a polylogue and review its theoretical treatment (section 2); 2) I discuss the underpinnings of the interaction-related notion of a fallacy and argue that room for a normative model of an argumentative polylogue should be made (section 3); 3) I analyze false dilemma, collateral straw man, as well as some other fallacies of argumentation from a polylogical perspective (section 4).

\section{Polylogue}

\subsection{Basic definitions}

A polylogue is what it says - a poly-logos, discourse ( $\lambda$ óros) between many ( $\pi \circ \lambda \cup$ ). For the current purposes, I divide all verbal activities into either mono-logues or dia-logues. ${ }^{1}$ Dia-logues comprise all interactive uses of language (to be precise: actual or explicit dialogues; internal or implicit dialogues are monological renderings of actual interactions). Based on the number of speakers, dia-logues - or simply interactions - are a genus that can be, quite straightforwardly, divided into the species of: di-logues, trilogues, tetra-logues, etc. Poly-logues are thus all dia-logues which are not dilogues. Please note the distinction between dia-logues and di-logues. They are often confused due to: 1) the easily overlooked difference in Greek terms (dia-logue: 'through' discourse; di-logue: discourse between 'two'); 2) the practice, deeply entrenched in both ordinary and academic parlance, of limiting a dia-logue to a di-logue. ${ }^{2}$ Here, I aim precisely to problematize this practice in argumentation theory.

Given the capacious, and very central, meaning of the notion of "logos" in ancient Greece - which may refer to a 'word,' 'discourse,' 'opinion,' 'thought,' 'account,' 'reason,' 'argument,' 'rule,' etc. ${ }^{3}$ - it is common to follow Aristotle and understand "logos" with a normative edge as 'rea- 
soned discourse' (e.g., Chen, 2010, p. 55; Johnson, 2000, p. 161). This paves the way for conceiving polylogues as 'reasoned' (based on reason-giving, argumentation) and thus, at least ideally, also 'reasonable' (intelligent) interactions between many. ${ }^{4}$ Therefore, in the following, an argumentative polylogue will be understood as a form of verbal interaction which involves argumentation between multiple parties with distinct positions. The notions of 'positions' and 'parties' are significant here. A position is a verbally expressed stance (standpoint) on a disputable issue formulated as an open Wh-question: Who should be Egypt's next president? How to solve the financial crisis? In this case, we can get a genuine multiplicity of positions simultaneously defended and objected to in a multi-party dispute: there can be 12 contenders for the president's office (as there were in Egypt in 2012), and there can be many competing proposals on how to best tackle the financial crisis (see Fairclough \& Fairclough, 2012)..$^{5}$ Unless they are some versions of one another, such positions are contrary: if one of them holds, others are refuted; however, if some of them are refuted, no definite conclusions about the others can be drawn. ${ }^{6}$ This is different from the polar yes/no questions, which allow for only two contradictory sides as answers: if one of them holds, the other does not, and vice versa (see Lewiński, 2013; Jacquette, 2007). ${ }^{7}$

Finally, parties are bearers of distinct positions along with the arguments supporting their positions: they are thus defined by what they hold and defend. In the course of argumentation, a party supports its position through arguments and starting points which build, presumably, a consistent commitment set (Hamblin, 1970; Walton \& Krabbe, 1995). Eventually, a party can be defined as a defender of an individual case, that is, an ordered set comprising the party's position and its commitment set. Based on this: 1) two arguers supporting the same position (e.g., "The revolution must continue!") are different parties, so long as they express some incompatible arguments in its support ("Because it will allow us to build an Islamic state" vs. "Because it will allow us to build a secular state"); ${ }^{8}$ ) a collectivity of participants (e.g., a political party in a parliament) is taken to constitute one argumentative party so long as they consistently argue for a given position (Lewiński, 2010). Such an understanding of argumentative polylogues differs from pragma-linguistic approaches distinguishing between each individual participant, ${ }^{9}$ and from general philosophical approaches where "participants need not be persons" (Sylvan, 1985, p. 89)..${ }^{10}$ It pictures argumentation as a clash of positions and arguments, rather than personalities, and thus focuses exclusively on elements pertinent to normative analysis of argumentation - a crucial requirement for discussing fallacies. 


\section{Marcin Lewiński}

\subsection{Polylogues in pragmatics}

The first discipline directly relevant to the investigation of argumentative polylogues is pragmatics (in a broad sense including conversation, interaction, and discourse analysis). ${ }^{11}$ Pragmatics - for instance in the form of Searle's (1969) speech act theory - starts from a simple schematic understanding of what interactions are:

The speech act scenario is enacted by its two great heroes, "S" and "H"; and it works as follows: $\mathrm{S}$ goes up to $\mathrm{H}$ and cuts loose with an acoustic blast; if all goes well, if all the appropriate conditions are satisfied, if S's noise is infused with intentionality, and if all kinds of rules come into play, then the speech act is successful and [...] is concluded and $\mathrm{S}$ and $\mathrm{H}$ go their separate ways. (Searle, 1992, p. 7)

Such grounding of the speech act analysis on the simplified dualistic categories of a unified Speaker and unified Hearer has been criticized from a variety of perspectives as not being fully adequate to the task of understanding the pragmatic working of language. To this end, some pragmatic analysts have called for a shift of focus from schematic representations of interactions to "the description of all the phenomena which characterize the functioning of polylogues" (Kerbrat-Orecchioni, 2004, p. 2). Empirical studies of the pragmatic and conversational features of multi-participant interactions have examined phenomena which extend well beyond the standard rules and conventions of dyadic encounters (di-logues). ${ }^{12}$ To start with, turntaking - which in a di-logue between speakers A and B naturally follows the $a-b-a-b$ sequences of 'adjacency pairs' (such as question-answer) - becomes a complex activity, with speakers often competing for the floor and generating convoluted patterns of conversations. ${ }^{13}$ One of these patterns is 'interlocutive crowding' (when various speakers' topical lines interfere with one another) leading to 'splitting and resumption' (when parallel sub-discussions between subgroups emerge and then re-converge; see Traverso, 2004). Polylogues also allow for co-production of discourse by different speakers vis-à-vis their listeners, such as when one arguer sides with another one and provides arguments supporting the other's position. ${ }^{14}$ Finally, to give but one more relevant example, speakers may strategically target their utterances to various ratified and non-ratified participants. Parents discuss between themselves, only to convey a message to their overhearing children, politicians speak to a journalist to challenge opponents and entice voters, etc. (see esp., Clark \& Carlson, 1982; Goffmann, 1981; Levinson, 1988). ${ }^{15}$ Characteristically, participants in polylogues skillfully design their discourse to take into account these phenomena. In this way, they orient their verbal contributions 
to the often implicit rules and conventions of polylogical verbal exchanges which are not covered by the dyadic (di-logical) concepts.

Accordingly, the basic criticisms of polylogue analysts concern the empirical validity of the dominant dyadic scheme used in conversation analysis (with the notions such as $a-b-a-b$ sequences of 'adjacency pairs') and speech act theory (felicity conditions defined in terms of dyads consisting of Speaker and Hearer): "Even if such a scheme is intended to be a model, for descriptive work it cannot be" (Hymes, 1972, p. 58). Thanks to their empirical orientation, pragmatic analyses of polylogues contribute a great deal to our understanding of the unique constraints and opportunities of actual multi-participant interactions. Yet, they reject the ambition of passing any normative judgments, whether regarding conversations at large, or their argumentative aspects in particular. Polylogical fallacies are not their concern.

\subsection{Polylogues in dialectics}

What remains to be investigated is how descriptive modeling of naturally occurring polylogues can be brought to bear on an interaction-based and normative argumentation theory, as developed, for instance, in dialectical models. If descriptive models of polylogues involve some additional rules and conventions for ordinary speakers, will normative argumentative models of polylogues also require some additional rules? If so, will these rules account for some new, polylogical, fallacies or at least provide a better account of the already recognized fallacies?

A good starting point for answering these questions are approaches to argumentation theory that are both dialectical and pragmatic. One such comprehensive approach is the pragma-dialectical theory of van Eemeren \& Grootendorst (1984, 2004). Pragma-dialectics offers a thoroughgoing conceptual synthesis between speech act theory and dialectical theory. In the pragma-dialectical model of a critical discussion, the Speaker and the Hearer act in their dialectical roles of the Protagonist and the Antagonist performing speech acts which have argumentative relevance (advancing a standpoint, challenging a standpoint, advancing arguments, asking critical questions regarding arguments, defining, etc.). The analysis thus shifts its focus from all speech acts to argumentatively relevant ones and from descriptive to normative concerns: fallacies are those argumentative speech acts which violate the rules of a critical discussion. The question of polylogical rules becomes relevant here. If, as argued extensively by pragmatic polylogue analysts, "the speech act scenario" requires serious elaborations to adequately describe polylogues, then a speech act based dialectical scenario probably requires some conceptual work too. ${ }^{16}$ 


\section{Marcin Lewiński}

However, even a formal dialectical theory (e.g., Barth \& Krabbe, 1982; Hamblin, 1970; Walton \& Krabbe, 1995) might need some extensions whenever its scope is extended beyond consideration of simple di-logues between a Proponent and an Opponent. Hamblin's position makes this clear:

The study of dialectical systems can be pursued descriptively, or formally. In the first case, we should look at the rules and conventions that operate in actual discussions: parliamentary debates, juridical examination and crossexamination, stylized communication systems, and other kinds of identifiable special context, besides the world of linguistic interchange at large. A formal approach, on the other hand, consists in the setting up of simple systems of precise but not necessarily realistic rules, and the plotting of the properties of the dialogues that might be played out in accordance with them. Neither approach is of any importance on its own; for descriptions of actual cases must aim to bring out formalizable features, and formal systems must aim to throw light on actual, describable phenomena. (Hamblin, 1970, p. 256)

Since Hamblin himself was "concerned mainly with two-person dialogues" 17 (1970, p. 257) argumentation in polylogues did not become an issue for him. Yet, some formal dialecticians have tried to bridge the gap between "actual, describable phenomena" of polylogues and "formal systems" by recognizing that not all dialogues involve just two parties. Prakken is one of them. His formal model of a "persuasion dialogue" consists of rules for only one Proponent and one Opponent, but that is because " $[\mathrm{t}]$ he remaining participants, if any, are the third parties with respect to [a thesis] $t$, assumed to be neutral towards $t "$ (Prakken, 2009, p. 286). That is to say, the stipulated neutrality of "third parties" in a dialogue annuls their relevance for modeling argumentation. The problem remains what to do with third parties which are not neutral towards a thesis, but instead propose a third option which is contrary to what the Proponent and the Opponent argue about. A simple example is given in the next section.

\subsection{Example: reciprocity vs. transitivity}

Before moving to the issue of polylogical fallacies, I will present a very simple example, which also serves as an introduction to the forthcoming complications. Consider the following fragment of a polylogue between three discussants:

A: I think we should buy an (A)merican Airlines ticket - it gets us from Lisbon to Windsor in a mere $16 \mathrm{hrs}$ for just $€ 800$.

B: I'm not so sure... Look! I found a (B)ritish Airways offer for the same price, and it takes only $14 \mathrm{hrs}$. 
In a di-logue, B (the antagonist of the (A)merican position and the protagonist of a contrary (B)ritish position) "wins" this line of argument without much ado $-\mathrm{s} /$ he has a (rather obvious) winning strategy. However in a polylogue, B can be easily "outflanked" by some other party, e.g.:

C: If $2 \mathrm{hrs}$ are so important to you, how about flying Air (C)anada: $12 \mathrm{hrs}$ for $€ 800$ !

We can see here that the simple dyadic reciprocity is extended by the problem of transitivity. A and B are not only accountable to one another (in that, for instance, they are expected to practice what they preach), but also to "someone else." In this case, the (B)riton is killed by the (C)anadian with her/his own weapon: a better deal $=$ a flight that is $2 \mathrm{hrs}$ faster at an equal price. Shortly, there is possibly a different set of considerations to be taken into account when practicing and evaluating polylogues (as opposed to simple di-logues).

\section{Fallacy}

\subsection{Hamblin: logic as part of a dialectical system}

Before discussing possible polylogical fallacies, it is worth mentioning the theoretical rationale behind considering them in the first place. Hamblin (1970) has convincingly argued that many of the so called fallacies of argument originated in "the context of disputation on the Greek pattern, as Aristotle originally intended it" (p. 33) and that they can "find their true modern home" in "the theory of the use of language in practical situations: what Carnap called Pragmatics and what we shall find reason to call Dialectic" (p. 40). He stands against some tenets of the formal logical and epistemic "concept of argument" and the resultant approaches to fallacies, which he deems, in some respects, insufficient or unnecessary (1970, Ch. 7). In a classical logical sense, begging the question is not an invalid inference, and a fallacy of many questions is not an inference at all. As is well known, Hamblin's solution is to construct formal dialectical systems in which, according to him, the notion of a fallacy can be most fully elaborated. That is because something is amiss in the mono-logical approach to argument that a well-developed dia-logical approach can fully grasp: ${ }^{18}$

Dialectic, whether descriptive or formal, is a more general study than Logic; in the sense that Logic can be conceived as a set of dialectical conventions. It is an ideal of certain kinds of discussion that the rules of Logic should be observed by all participants, and that certain logical goals should be part of the general goal. (Hamblin, 1970, p. 256) 


\section{Marcin Lewiński}

It is clear that Hamblin does not aim to replace Logic with dialectics. He instead argues, to use Wittgenstein's expression, ${ }^{19}$ that Logic is best conceived of as a certain precisely "circumscribed region" (subset) within a broader dialectical system (superset). Thus, a dialectical system can embrace as "its own" all the logical fallacies (namely, failed deductive, and also inductive, inferences), and add those that are purely dialectical (by Hamblin's reading): e.g. begging the question (petitio principii). They can simply be called dialectical fallacies. Fallacies in general are thus violations of the rules of dialectical systems - systems of regulated (reasonable, intelligent, rational, critical) dialogue. Interestingly, while a dialogue may "have a number of participants - in the simplest case, just two" (Hamblin, 1970, p. 255), Hamblin's systems are exclusively dyadic (the two participants are Opponent and Respondent or Questioner and Answerer). So how about dialogues with a number of participants exceeding two (polylogues)? Will they be defined by the same rules and thus involve precisely the same fallacies? Or will they generate some additional (or different) norms of reasonableness?

\subsection{Sylvan: dialectics as part of a polylogue system}

Some preliminary answers to these questions have been given by Richard Sylvan (aka Richard Routley) in a paper "Introducing polylogue theory" ("dedicated to the memory of Charles Hamblin"):

Polylogue generalises upon dialogue. [...] Dialogue suggests, for one thing, a central focus, a spotlight on one person, the speaker, at a time - limitations that polylogue can abandon. Dialogue is a conversation or discourse between two or more persons. No restriction to two persons is implied by the term dialogue, though a two party form is commonly suggested by use of the term. [...] Use of the term polylogue is designed to break all such presuppositions. [...] Finally, the sole participant in a polylogue may be an eccentric hermit or an artificially isolated reasoner: polylogue includes monologue. (Sylvan, 1985, pp. 89-90)

It seems as though Sylvan takes Hamblin's reasoning to its logical consequence, and suggests a yet bigger superset - later defined as a polylogue system - which includes the study of reasoned monologues (logic), dialogues (dialectics), and more. While for Hamblin logic is a certain precisely circumscribed part of the dialectical system, for Sylvan Hamblin's dialectical discussions are in turn special sub-systems within a polylogue - with their additional assumptions and limitations; e.g., a discussion is focused on one central issue debated by two persons. As such, dialectics does not cover the whole story. So what is the rest of the story? 
For Sylvan, it is a polylogical system of communication, not unlike a computer network, with numerous connections between multiple participants. Polylogues involve "holistic restraints" defined through "certain sets of rules" (1985, p. 96) which control phenomena extending beyond simple dyadic interactions. Sylvan does not explicitly put it this way, but polylogues basically require looking anew at the notion of common ground, a central feature of dialectical (and also rhetorical) approaches to argumentation. In a dyadic encounter, common ground is what is shared by the two interlocutors - it is there or it isn't, and when it isn't, any reasonable communication, let alone argumentation, is precluded ("sorry, I don't speak your language"; deep disagreement; see Fogelin, 1985). In a polylogue, one can distinguish between a global common ground, what is shared among all participants, and some local common ground $s$, what is shared by some subset of participants. ${ }^{20}$ For instance, linguistic rules need not be fully shared: "a polylogue is not ill-formed should it include sub-dialogues in different languages" (Sylvan, 1985, p. 96) - one can resort to other participants as translators and communicate reasonably without common language. Similarly for logical rules and commitment rules: new solutions (e.g., some metasystem of translation between various logics) need to be found to account for a reasonable multiplicity of logics and complex commitment stores in one multi-party discussion. This is what Sylvan begins doing, even though he considers it to be "a rather academic concern" (Ibid.). What is surely not a purely academic concern is the simple observation that polylogues require a different set of procedural rules: compare the discussion procedure of a dyadic legal trial with a parliamentary debate to which many members of various parties contribute. Speaking of Hamblin's dialectical systems, Sylvan claims that "there is little doubt that his rules resemble the rules of court procedure and order" (1985, p. 110). By contrast, polylogues would require something akin to the famous Robert's Rules of Order meant to secure an orderly conduct of multi-party assemblies (1985, pp. 102-103). This difference in discussion procedures is significant, as different verbal interventions would be relevant ('in order,' 'legal,' 'acceptable') in court and in an assembly. Importantly, procedural rules alone cannot define all fallacies: "What is in order, such as properly affirming the consequent, may be fallacious" (Sylvan, 1985, p. 103). All the same, taken together "the rules controlling polylogues" (1985, p. 96) - namely: linguistic, logical, commitment and procedural rules - can be instrumental in normatively defining rationality and its flipside, fallaciousness. Similarly to Hamblin's dialectical systems (1970, Ch. 8), the analysis of polylogue systems can be conceived of as either a descriptive or a formal (and normative) undertaking; therefore, 


\section{Marcin Lewiński}

"polylogue theory [...] affords a setting for theories of dialogue, conversation and communication, and differently, for a theory of fallacies" (Sylvan, 1985, p. 107). However, Sylvan stops short of even sketching any such polylogical "theory of fallacies."

\section{Polylogical fallacies}

\subsection{False dilemma}

\subsubsection{Example}

Good examples of polylogues are easily found in political discourse. Take for example discussions during the first free presidential elections in Egypt in spring 2012 - a year after president Mubarak's 30-year-long dictatorial rule ended in a revolutionary upheaval. Considering Egypt is a presidential republic, the immediate electoral question - Who should be the president? can also be formulated as a basic political issue: Who should govern Egypt? Many views emerged on this issue, with three of them dominating the public discourse: 21

1) Morsi: Muslim Brothers! (Islamist anti-regime)

"I will go on with the challenge of knocking down the corrupt regime. [...] I am the legitimate candidate, the candidate of the revolution and the revolutionaries."

2) Shafiq: Mubarak's supporters! (secular pro-regime)

"I represent the civil state and the Al Ikhwan (the Muslim Brotherhood) represents the sectarian state. [etc. - ML] I represent stability and they represent chaos and hindrance to people's lives."

The debates between the Islamist Morsi and an ex-regime official Shafiq are interesting examples of a dialectical clash of what seem to be contradictory positions. In pragma-dialectical terms, Morsi and Shafiq engage in a clearcut mixed difference of opinion (van Eemeren \& Grootendors, 2004, p. 60). Interestingly, if they share any common ground, it is the idea that differences between them are contradictory: if one is right, the other is wrong, and vice versa. This is evident in the terms they use: corrupt-legitimate, civil-sectarian, stability-chaos. They thus "dichotomize" the debate (Dascal, 2008) by constantly resorting to mutually exclusive and, possibly, jointly exhaustive dyads. However, even if their discussion follows some dialectical rules, it does not exhaust the political disagreement space - there is at least one more prominent position on the issue: 
3) Sabahy: Progressives! (secular anti-regime)

"I am not supporting the reproduction of the Mubarak regime nor am I supporting the continuation of the domination of the Islamic current."

Sabahy's position thus "de-dichotomizes" the debate by "showing that the opposition between the poles can be constructed as less logically binding than a contradiction, thus allowing for intermediate alternatives" and by "actually developing or exemplifying such alternatives" (Dascal, 2008, p. 35). So what is the problem here? In the language of fallacies, Morsi and Shafiq seem to be ensnared in a false dilemma: an unjustified (false) division of an issue into but two propositions $(\delta i-\lambda \varepsilon \mu \mu \alpha)$. In the following, I argue that the fallacy can best be understood as a polylogical fallacy of confrontation. That puts me in an awkward position - after all, there is already a logical and a dialectical treatment of a false dilemma. But is there really?

\subsubsection{False dilemma in logic}

Let us start with Tomić's (2013) "systematic exposition" of a false dilemma on logical grounds. Tomić, before moving on to her own proposal, critically analyzes the treatment of the dilemma in logic/argumentation literature. Notably, she claims that false dilemma should not be treated as an unsound use of the valid form of disjunctive syllogism due to "an incomplete or misleading disjunctive premise" (2013, p. 349).

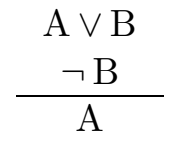

1a. Valid disjunctive syllogism

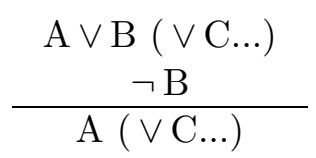

1b. Fallacious disjunctive syllogism

Figure 1. False dilemma as a fallacious disjunctive syllogism ("Hidden" premises and conclusions in brackets)

On this reading, a fallacy is committed when the first premise $(\mathrm{A} \vee \mathrm{B})$ is a misrepresentation of an actual larger disjunction $(\mathrm{A} \vee \mathrm{B} \vee \mathrm{C} . .$.$) ; in this$ case, the inference to the proposition A is not valid anymore. However, as Tomić argues, this and other similar forms of reasoning "do not rely on the argumentation schemas/argumentation structures of dilemma-reasoning" (2013, p. 350). According to her, false dilemma is best explained as a failure in applying the logically valid forms of constructive and destructive dilemmas. Since there are two basic types of failure (incomplete disjunction and incomplete consequence), we obtain "four types of false dilemma." 

$\mathrm{A} \vee \mathrm{B}$
$\mathrm{A} \rightarrow \mathrm{Z}$
$\mathrm{A} \vee \mathrm{B}(\vee \mathrm{C} \ldots)$
$\mathrm{A} \rightarrow \mathrm{Z}$
$\frac{\mathrm{B} \rightarrow \mathrm{Z}}{\mathrm{Z}}$
2a. Valid (simple)
constructive dilemma
2b. False (simple)
constructive dilemma
(incomplete disjunction)

$$
\begin{gathered}
\mathrm{A} \vee \mathrm{B} \\
\mathrm{A} \rightarrow \mathrm{Z} \\
\mathrm{B} \rightarrow \mathrm{Z} \\
(\mathrm{A} \rightarrow \mathrm{Y}) \\
(\mathrm{B} \rightarrow \mathrm{Y}) \\
\hline \mathrm{Z}(\wedge \mathrm{Y})
\end{gathered}
$$
2c. Defeasible sound (simple) constructive dilemma (incomplete consequence)

Figure 2. False dilemma as a fallacious (simple) constructive dilemma ${ }^{22}$ ("Hidden" premises and conclusions in brackets)

To cut Tomić's long story short, the first failure occurs when "the actually provided argument is deductively valid but has a false disjunctive premise and is therefore not sound" (2013, p. 351). Importantly, the disjunctive premise is false, because it is "incomplete" (pp. 352-353); e.g. A $\vee \mathrm{B}$ should in fact be $A \vee B \vee C$ (see Figure 2b.). The other failure is due to "neglecting other relevant information" in the premises of the argument, namely, "the possible positive consequences of the given disjuncts" (p. 358) for the constructive type (premises ' $\mathrm{A} \rightarrow \mathrm{Y}$ ' and ' $\mathrm{B} \rightarrow \mathrm{Y}$ ' in Figure 2c) and, conversely, the possible negative consequences for the destructive type. In the former type (2b: incomplete disjunction), an argument is fallacious, for even if deductively valid, it is unsound. In the latter type (2c: incomplete consequence), an argument is deductively valid, even sound!, but it is still fallacious, since some additional information regarding the consequences of the premises can defeat it. I refrain from discussing the logical details of Tomić's account, which seem rather controversial.23 Regardless of this, while her logical analysis might tell us where the problem lies, it also tells us it does not lie within logic. Rather than in inferential relations, it lies in the content of the premises, and I doubt if logic is interested in inviting such problems home. Copi and Cohen are quite blunt about it: since it is a valid form of inference, "[f]rom the strictly logical point of view, the dilemma is not of special interest or importance" (1990, p. 245); it is instead a practical problem of rhetorical controversies. As I will argue, this is so because it precludes the expansion of a debate that can expand by involving extra positions (extra disjuncts or consequences).

\subsubsection{False dilemma in dialectics}

For dialecticians, such as van Eemeren and Grootendorst, a false dilemma occurs when "a contrary opposition is presented as a contradiction": 
It is then suggested that there are only two options and if one of them cannot be proved to be the case, it is concluded that this is not the case (the "ordinary" argumentum ad ignorantiam) and hence that the other option is the case. All other possibilities are then glossed over. (1992, p. 190)24

Similarly to above, I will not discuss all the details of their treatment of the fallacy. But it is important to stress that van Eemeren and Grootendorst discuss these problems among "fallacies in concluding the discussion": false dilemma in combination with ad ignorantiam amounts to a fallacy of "making an absolute of the failure of the defense" (1992, p. 187ff.). However, when they speak of "two options" and "other possibilities," they clearly mean standpoints: it is the status of defended and challenged standpoints that is being decided at the concluding stage. So the false dilemma seems to be in fact a fallacy of "glossing over all other" standpoints that pertain to the issue. This is significant, since the standpoints to be discussed are determined at the very first stage of a critical discussion - confrontation rather than the last, concluding stage. So let us look there.

The very first rule of the confrontation stage of a critical discussion is: Discussants may not prevent each other from advancing standpoints or from calling standpoints into question (van Eemeren \& Grootendorst, 2004, p. 190). By quickly examining the plurality here ("discussants" = the protagonist + the antagonist; "standpoints" $=+/ p$ or $-/ p)$, we realize it actually amounts to no more than duality. To understand why this is so, we need to begin even before the pragma-dialectical beginning, formulated as follows: "A dispute arises when someone advances a standpoint and someone else casts doubt upon it" (van Eemeren \& Grootendorst, 1992 , p. 107). However, a standpoint itself can be seen as a response to a more or less explicitly stated issue that instigates position-taking, such as a problem that calls for a solution through practical reasoning. Now, the issue can be expressed through one of the two grammatically available types of questions: 1) a yes/no question, which allows for two relevant responses (either yes or no), and thus for two contradictory sides $(+/ p$ or $-/ p$ ) as standpoints; 2) an open Wh-question, which allows for a number of relevant responses, and thus possibly an open set of contrary positions $(p, q, r, \ldots)$ as standpoints. ${ }^{25}$ Traditionally, the building blocks of dialectics are yes/no questions:

[...] not every universal seems to be a dialectical premise, e.g. "What is man?", or "In how many ways is the good said?" For a dialectical premise is that in response to which it is possible to answer yes or no; but this is not possible in response to these questions. (Aristotle, Topics, 158a14-18) 


\section{Marcin Lewiński}

Problematic questions concern alternatives "Is two-footed land animal the definition of human, or is it not?" (10lb26-37) "Are perception and knowledge the same or different?" (102a7) "Is every pleasure a good?" (108b35). Problems thus require the dialectical respondent to adopt one or the other side of an alternative [...]. (Lennox, 1994, p. 55; see also Krabbe, 2006, p. 186, and Spranzi, 2011, Ch. 1)

As dialectical disputations start from "a problem [that] is a two-sided question" (Smith, 1989, p. 148, cited in Lennox, 1994, p. 56) or a "contradictory alternative" (Lennox, 1994, p. 60), they cannot but be clashes of two contradictory sides of the problem observing the law of excluded middle ( $p \vee \neg p)$. As a result, the Aristotelian tradition of dialectics is, so to speak, an utterly dilemmatic business: dialectical procedures unfold through a series of dilemmas ("Is it the case, or not?"). What does not fit the contradictory form - basically, open issues formulated as Wh-questions: "What is man?", "Who to elect?", etc. - is not suitable for dialectical treatment. Instead, it belongs to the sciences or rhetoric. If this is so, there is no room within dialectics for a false dilemma which "involves the confusion of a contrary and a contradictory opposition" (van Eemeren \& Grootendorst, 2004, p. 182) - there is simply no contrariness that would cause confusion. Similarly to logic, false dilemmas are alien intruders. ${ }^{26}$

\subsubsection{False dilemma in a polylogue}

As proposed above (section 2.1), in contrast to dialectics, a discussion over multiple contrary positions on an open issue instigated by a Whquestion is a defining feature of polylogues. In a context where one can discuss many propositions (poly-lemma), a di-lemma is false, because it focuses exclusively on two positions, thus preventing other positions (standpoints) from being considered. In this sense, I fully agree with van Eemeren and Grootendorst that a false dilemma consists in an unjustified reduction of contrary options to only two, taken to be contradictory. The difference is that I would call a system that allows for a clash of multiple contrary positions a polylogue, while they will reconstruct it as a critical discussion. (As argued in much detail in Lewiński \& Aakhus, forth., a reconstruction of a polylogue in terms of multiple dyadic discussions is suspicious as a move from the polylogical whole to locally isolated dyads.) Moreover, the false dilemma seems to be best grasped as a fallacy of polylogical argumentation by virtue of violating a basic rule of confrontation: Discussants may not prevent each other from advancing standpoints that reads here: 'all parties to a polylogue should be free to advance their, possibly contrary, positions' (and further discuss them). Anyone who tries to reduce this open set of con- 
traries to a closed dichotomy based on contradiction and proceed with an elegant dyadic discussion, may be guilty of the dichotomization of the disagreement space - the false dilemma. (Note that I define parties as bearers of positions and arguments. An individual reasoner considering various "options" is engaged in an inner polylogue - similarly to inner dialectics, that is, "two-sided dialectics for an individual thinker", Jacquette, 2007, p. 117.) ${ }^{27}$ It is exactly here, in other words, where "incomplete disjunctions" - a chief concern for Tomić - are created. They are incomplete whenever the set of relevant answers to an open Wh-question is unjustifiably closed. In the argumentative framework followed here, competing answers to questions amount to positions that different parties take and defend when challenged.

I will conclude by acknowledging my debt to Hamblinian "logic" here: as he argued, while petitio principii and many questions are considered logical fallacies, they cannot be properly accounted for in classical logical terms (logicians deny that; see n. 18) - something akin to the status of long-term illegal immigrants: they reside, but without proper papers. They can get these papers in formal dialectics. I am arguing something similar for the false dilemma - while it is a fallacy fully recognized both in logic and dialectics, the explanations of its fallaciousness lie outside of logic and dialectic. Only in a polylogue can the fallacy receive a (fairly simple, no doubt) consistent and immanent treatment.

\subsection{Collateral straw man}

The dialectal fallacy of the straw man denotes a misrepresentation of someone's position attempted in order to easily refute that position. An argumentative move that involves a straw man can be characterized by two constitutive elements (Lewiński, 2011): the function of refuting an opponent's position and the form consisting in various methods of misrepresentation of the original position (misquotation, selective quotation, taking out of context, attacking a fictitious opponent, etc.). A simple example of the straw man may be:

Student: My work is progressing well, because many of the chapters of the thesis are completed.

Supervisor: Well, if everything is done, then why not submit it tomorrow?

Student: I never said everything, just many of them.

Despite claims that the straw man is "a common, familiar, and thoroughly theorized fallacy" (Talisse \& Aikin, 2006, p. 349), there seems to be a rather inconspicuous polylogical variant of the straw man. Consider the following (constructed) exchange: 


\section{Marcin Lewiński}

Shafiq: $\quad$ Our chief goal should be stability and peaceful continuation of Egypt's progress.

Morsi: No! We should progress by removing all the remnants of Mubarak's regime and installing a new Islamic order that the people of Egypt want.

Shafiq: $\quad$ Competent people who served our country well should remain in power. If we continue the revolution, we'll soon have a second Iran here.

Sabahy: It's not true. Everything depends on how we lead the revolution - an Islamic republic is neither a necessary nor welcome outcome of removing Mubarak!

Shafiq: How bizarre - you were just saying that the people of Egypt crave for a new Islamic order!

Sabahy: It wasn't me, it was this jerk Morsi.

What we note here is some form of conflating opposing positions. Shafiq tries to pinpoint an inconsistency in Sabahy's position by using Morsi's statements - as if Morsi and Sabahy held an identical position with the same set of commitments. They clearly do not, and so we are dealing with an attack on a position that Sabahy does not actually endorse. Sounds like a good scenario for the straw man fallacy. But again, dialectics would not tell us everything about it.

In pragma-dialectics, a straw man is a violation of rule 3 for critical discussion: Attacks on standpoints may not bear on a standpoint that has not actually been put forward by the other party (van Eemeren \& Grootendorst, 2004, p. 191). How does this rule apply to our example? Shafiq's attack is not a misrepresentation of his only opponent's ("the other party") position (a straw man sensu stricte), an attack on selected weak elements in a position (a 'weak man'), or on an entirely fictitious position (a 'hollow man') (see Aikin \& Casey, 2011). Instead, it is a faithful attack on a central argument of a real opponent - just not precisely the right one. The kind of straw man committed - let us call it a collateral straw man - occurs due to responding to "another other," a category that dialectical rules may find hard to grasp. ${ }^{28}$ Shafiq attacks Sabahy-opponent by attributing to him, quite faithfully, the commitments of Morsi-opponent. Of course, in a strict dualistic reconstruction isolating the discussion between Shafiq and Sabahy, Shafiq is obviously attacking a fictitious opponent, since Morsi does not belong to this very dyadic exchange. Yet in such a reconstruction something is missing, a crucial strategic aspect: someone "has actually put forward the (sub-) standpoint" that "the people of Egypt want Islamic rule"; and not a random someone, but a distinct opponent (another other) from the same side of the revolutionary barricade. So we have here 
a new sub-species of the straw man fallacy, distinguishable on polylogical grounds.

To recap, in our example Sabahy becomes a victim of collateral damage due to Shafiq's insensitivity to distinguishing opponents in a polylogue. His straw man consists not in the known forms of misrepresentation, but rather in attributing some actual commitment to an insufficiently differentiated opponent. This fallacy can be properly analyzed only in a polylogue. While it can be easily recognized on dialectical grounds, some basic insight into how it happens and why it may be successful would be missing in a dyadic account.

\subsection{Other fallacies from a polylogical perspective}

I began my discussion of polylogical fallacies with a false dilemma - that is because it seems to be the starting point for all kinds of troubles related to polylogical argumentation. As argued above, the dilemma is related to what might be called - after pragma-dialectics - the first rule of polylogical confrontation stage. Indeed, rules of any model of argumentation understood as intelligent interaction (or dialogue) need to require, at the very outset, a clear formulation of what is at issue in argumentation - in particular, which type of question arguers are dealing with. Yes/no questions ${ }^{29}$ can be handled through rules of a standard dialectical inquiry between two opponents. Safe Wh-questions with only two contrary answers (e.g., "Which of the divorced parents should have exclusive custody of the child?") also lend themselves to a dyadic dialectical discussion in which the relative merits of the two positions are judged. Moreover, discussion of multiple positions can possibly be split into a number of dyadic argumentations; then again, standard dialectical procedures may work. However, if there is no viable way to "dichotomize" a finite set of multiple positions, or a set is open-ended (as in risky Wh-questions), then arguers should recognize they are dealing with a genuinely multi-party disagreement space that should be explored as such through polylogical argumentation. Ideally, all possible mutual relations between multiple positions should be clearly defined by the arguers (for instance using the classic Aristotelian "square of opposition" which distinguishes between contradictory, contrary, sub-contrary, and sub- and super-altern relations). Having done that, arguers would be in a good position to see "what is at stake" in the polylogue.

On this procedural account of argumentation and fallacies, a false dilemma would be the first obstacle in properly investigating the issue and critically examining different positions on it through argumentation. This is not the only obstacle, however. Indeed, looking at the rules of a fully elaborated dialectical model - such as offered in pragma-dialectics (van 


\section{Marcin Lewiński}

Eemeren \& Grootendorst, 1992; 2004) - one can provide a fairly comprehensive overview of polylogical complications in fallacy judgments. Since there is no room to do so here, I will mention only three of them - in addition to the already discussed Rules 1 (related to the false dilemma) ${ }^{30}$ and 3 (related to the straw man) of the pragma-dialectical critical discussion.

Rule 4 (Standpoints may not be defended by non-argumentation or argumentation that is not relevant to the standpoint; van Eemeren \& Grootendorst, 1992, Ch. 12; 2004, Ch. 8) raises the question of relevance in multiparty argumentation. The scope of what amounts to "argumentation that is relevant to the standpoint" seems to be broadened. For example, seemingly irrelevant arguments that refute one of the standpoints expressed in a polylogue that is contrary to a defender's standpoint may well be relevant in supporting the latter standpoint. Schematically, arguer A may defend position $a$ in response to arguer B (holding position $b$ ) by trying to refute some basic arguments for a third position $c$ (defended by another party, C). Locally, taking it as A's defence against B's challenge, the refutation of $c$ seems irrelevant. Yet, globally, it might constitute a relevant argumentative speech act. Imagine, for example, a socialist arguing in a TV debate with a liberal that a socialist candidate should be elected, since she is a champion of secular education free of religious concerns. Since the liberal candidate has precisely the same approach to education, this argument seems to be irrelevant in judging the relative merits of the two candidates. But in a broader discussion, which includes the candidate of religious conservatives, this is surely a relevant (counter-)argument. These considerations would of course call for a reappraisal of the classic fallacy of relevance: ignoratio elenchii (see Hamblin, 1970; Walton, 2004).

Rule 6 (Discussants may not falsely present something as an accepted starting point or falsely deny that something is an accepted starting point; van Eemeren \& Grootendorst, 1992, Ch. 14; 2004, Ch. 8) stipulates that arguers should faithfully represent the starting points and commitments upon which they intersubjectively agree during their discussion. But such agreements gain in complexity when more than just two parties are involved. In general, all kinds of intersubjective procedures defined by pragmadialecticians for the argumentation stage (van Eemeren \& Grootendorst, 2004, pp. 145ff.) require a more complex notion of intersubjectivity and common ground - for instance, as discussed above (section 3.3), divided into a global and local level. What is (locally) shared by two parties is not necessarily shared by most or all parties. Should arguers be allowed to use premises that are acceptable to only a subset of parties? Will they not be guilty of the fallacy of evading the burden of proof vis-à-vis the parties 
that do not accept the premises? Eventually, deciding which argument or criticism holds and is thus decisive in the current discussion is much more complex in a polylogue than it is in a dyadic exchange.

Finally, a polylogical approach may bring about a better understanding of ad ignorantiam fallacy which, in pragma-dialectics, is a violation of Rule 9 (Inconclusive defenses of standpoints may not lead to maintaining these standpoints, and conclusive defenses of standpoints may not lead to maintaining expressions of doubt concerning these standpoints; van Eemeren \& Grootendorst, 1992, Ch. 17; 2004, Ch. 8). Along Walton's (1992) exposition, some conclusions from ignorance are drawn validly due to an "epistemically closed" (p. 381) knowledge base (e.g., I know a pen is in one of the five drawers and four drawers are empty, so: the pen is in the last drawer). A polylogical interpretation of this is straightforward: if a polylogue is instigated by a question intersubjectively deemed to be a safe Wh-question, and the list of competing answers qua positions is closed, then the refutation of all but one position (say: $x$ ) is a proof that position $x$ holds. Open risky questions do not allow that: the set of answers is in principle open-ended so all of the considered contrary positions might be wrong. In this case, concluding from ignorance that a given position holds is fallacious. ${ }^{31}$

\section{Conclusion}

In order to pass well-justified fallacy judgments there needs to be a rationale on the basis of which fallacious arguments are considered a breach of rationality. Much effort in argumentation theory is dedicated to precisely this goal: to provide a consistent model or system of argumentation governed by the rules whose breaches constitute fallaciousness. This applies equally to logical, dialectical and, I would add, polylogical fallacies. While quite obviously I have offered no such model here, I hope to have raised some concerns that have a broader relevance for the study of multi-party argumentation. I have theoretically justified the polylogical stance on argumentation and presented a polylogical account of two fallacies: false dilemma and collateral straw man. Importantly, I have argued that any model of polylogue similarly to Hamblin's dialectical systems - should not amount to a substitution of extant models (such as pragma-dialectical critical discussion) but rather a friendly extension that acknowledges their validity while adding some extra insights, both descriptive and normative, to the functioning of argumentation in a multi-party context. 


\section{Marcin Lewiński}

Further normative work on polylogical argumentation can be developed in two directions: one of them is the issue of polylogical fallacies, arguments that are either considered completely fine or are considered fallacious without a solid grounding in logical and dialectical theories, but are clearly unreasonable contributions to a polylogue. The other one is the converse problem of arguments that are well-defined fallacies on logical or dialectical grounds, but perhaps are fine in a polylogue. Above, I mentioned certain forms of irrelevance: when an argument seems out of place in a one-on-one encounter, but then "regains" relevance when the broader polylogue is considered. To consistently pursue either of these ways, further work on a model of argumentative polylogue has to be undertaken.

Acknowledgements. An earlier version of this paper was presented at the 10th International Conference of the Ontario Society for the Study of Argumentation (OSSA) "Virtues of Argumentation", 22-26 May 2013, Windsor, Canada. The work is supported by two projects of the Portuguese Foundation for Science and Technology (FCT: SFRH/BPD/74541/2010 and PTDC/FIL-FIL/10117/2009).

\section{N O T E S}

${ }^{1}$ I only take the number of speakers into account here without considering numerous value-laden concerns which typically make dialogue a special - constructive, open, and respectful - form of interaction. For instance, Perelman \& Olbrechts-Tyteca (1969, p. 37) distinguish between (heuristic) dialogues $=$ discussions and (eristic) debates .

2 For a further elaboration of these two points, see esp. Kerbrat-Orecchionni (2004) and Levinson (1988). For the routine of limiting dia-logue to a di-logue in argumentation theory, see Lewiński (2012, pp. 227ff.).

3 See, e.g., the entry for ' $\lambda$ ó $\gamma o \varsigma^{\prime}$ in A Greek-English Lexicon by Lidell \& Scott, available here: http://www.perseus.tufts.edu/hopper/text?doc=Perseus\%3Atext\%3A1999.04.0057 $\% 3$ Aentry\%3Dlo\%2Fgos.

4 "A positive understanding of the term [polylogue - ML] finds many different ways of thinking reconciled and articulated reasonably" (Chen, 2010, p. 55).

5 The examples given here and below are all cases of practical reasoning driven towards (a disposition/intention to some) action. In this case, the number of contrary positions is demarcated by the set of answers to the "What to do?" question. However, similar multiplicity might occur in the case of theoretical reasoning dealing with the questions of truth ("What is the case?"). For instance in science, a number of competing hypotheses might be defended and tested by different groups.

${ }^{6}$ Note that Wh-questions can be safe when they are "demanding choices between specified finite sets of alternative statements" or risky when relevant answers constitute an open-ended set of alternatives (Hamblin, 1970, p. 216). In the case of safe questions, after having properly refuted all but one contrary position (proposals, hypothesis), the last one holds by elimination (via a valid disjunctive syllogism; see section 4.3). In the case of risky questions, no such conclusion can be reached (the options might be all wrong). 


\section{Argumentative Polylogues: Beyond Dialectical Understanding of Fallacies}

7 This applies to traditional bi-valued logic. Tri-valued logic (such as, e.g., used by pragma-dialecticians, see van Eemeren \& Grootendorst, 2004) allows for a third option: 'X neither holds nor doesn't hold' (the 'I don't know' answer). Finally, proponents of para-consistent logics legitimize the fourth option: 'X both holds and doesn't hold' (see Sylvan, 1985). While I refrain from embracing para-consistencies, I only note that trivalued logic does not generate a polylogue in the sense defined above: since one does not have to argue positively for doubt, it does not constitute a distinct position.

8 Note that this is consistent with Quine's (1959; Quine \& Ullian, 1970) take on the verification of beliefs: in most cases, we do not simply verify an individual proposition (here: position), like dialectics tends to do, but rather an ordered "web" of propositions (here: case), one of which is singled out for testing. This testing, however, is never fully independent from the acceptability of other assumptions (here: commitments).

9 “[...] [W]e will not speak of 'multi-party conversations' but of multi-participant conversations, or rather multi-participant interactions [...] Thus, we will refer to as polylogal all communicative situations which gather together several participants, that is, real live individuals." (Kerbrat-Orecchioni, 2004, p. 3, italics original).

10 "In a polylogue the participants need not be persons; some or all may be computers, as in a parallel computing network. The folklore committee comprising three men and a dog furnishes a polylogue setting." (Sylvan, 1985, p. 89).

11 From a different perspective, also "intercultural philosophers" emphasize "the need of polylogic argumentations" (Wimmer, 1998, p. 8; Wimmer, 2007) understood as situations in which "individuals are confronted with several dialogue partners from different cultures simultaneously" (Chen, 2010, p. 54).

12 Various aspects of polylogical conversations have been tackled, among others, by: Bruxelles \& Kerbrat-Orecchioni, 2004; Clark \& Carlson, 1982; Goffman, 1981; Goodwin \& Goodwin, 1990; Haviland, 1986; Hymes, 1972; Kerbrat-Orecchionni, 1997, 2004; Levinson, 1988; Maynard, 1986; Traverso, 2004.

13 "As for the alternating pattern, the famous ababab formula only works for dilogues, whereas for trilogues the alternation does not respect any kind of fixed rules: we are dealing with an infinite number of possibilities, the abcabcabc model being very exceptional" (Kerbrat-Orecchionni, 1997, p. 5).

14 In their study of group discussions, Canary, Brossman, \& Seibold (1987) described the structure of a tag-team argument occurring "when two individuals jointly formed a single argument" (p. 29). Note that for them "argument structures are rules and resources that are produced and reproduced in argumentative discourse" (p. 20). Bruxelles \& KerbratOrecchioni (2004) similarly discuss discursive patterns of "coalitions in polylogues."

15 For thorough speech act analyses of many ordinary examples of how we craft our natural discourse to address many Hearers in a polylogue, see Clark \& Carlson (1982), e.g., on p. 364:

"With ordinary linear indirectness, utterances can become very complicated; but with lateral indirectness, the possibilities almost defy imagination. For a relatively simple example, consider this:

(67) Ann, to Barbara, in front of Charles, David, and Ewan: Barbara, I insist that Charles tell you the joke about the two Irishmen."

According to Clark \& Carlson, as related to different (groups of) listeners, this speech act is at the same time an assertion, a request, and a warning. This nuance would be missed in a framework consisting of the Speaker and the Hearer.

16 Pragma-dialecticians recognize some of the polylogical elements of ordinary argumentation - for instance, arguing one's case simultaneously against different "audiences" - but they consider them to be rhetorical complications of certain communicative activity types which do not affect the dyadic dialectical model (see van Eemeren, 2010, esp. Chs. 4 \& 5). 


\section{Marcin Lewiński}

17 Indeed, exclusively.

18 Although, expectedly, proponents of logical approaches deny that: petitio pricipii, they argue, can be fully elucidated "on entirely logistical principles" in a way "closely resembling the Standard Treatment" (Botting, 2011, p. 23).

19 Wittgenstein criticizes St. Augustine's description of language ("a system of communication") in the following way: "Yes, it is appropriate, but only for this narrowly circumscribed region, not for the whole of what you were claiming to describe" (Philosophical Investigations, §3).

20 "Even if the principle 'No common logic, no communication' held, it would not follow that there must be a one logic for each polylogue, only common ground for each pair of parties in a polylogue that manage to communicate" (Sylvan, 1985, p. 110). Of course, on the flipside, there is always a danger that in a polylogue "different voices are ensnared in their own particularities; consequently, no common ground can be found" (Chen, 2010, p. 55).

21 The examples - when in quotation marks - are actual fragments of political discourse translated from Arabic by D. Mohammed, and used in Lewiński \& Mohammed, 2012. When not in quotation marks (see section 4.2), they are loose paraphrases of actual discussions.

22 I limit myself here to presenting this type of false dilemma. Schemas for (valid and fallacious) complex constructive dilemmas and (simple and complex) destructive dilemmas can easily be generated along the same pattern and can be found in Tomić (2013).

23 As rightly pointed out by one of the reviewers, Tomić might by guilty of "mixing" monotonic and non-monotonic logic "to produce a confusing result." Indeed, in (2013, Sec. 3.2) Tomić argues that "it is possible to defeat deductively valid arguments with true premises" and provides six necessary conditions for this to happen.

${ }^{24}$ I do not take them to refer here specifically to the fallacy of illicit contrary as formally described in Aristotle's term logic, committed when a contrary relation between propositions is taken to be contradictory. For instance: one resorts to the principle of contradiction to infer from the negation of a universal affirmative proposition (It's not true that "all dogs are black") the truth of a universal negative proposition ("No dogs are black"), while these two universals are merely contrary: they cannot both be true, but they can both be false (It's neither true that "all dogs are black" nor that "no dogs are black"). A correct contradictory inference is, of course, a particular negative ("Some dogs are not black").

\section{See above Sec. 2.1 and esp. n. 6 and 7 for further elaboration.}

26 Admittedly, pragma-dialectics, due to its tri-valued logic, is not Aristotelian dialectic. It allows for the "I don't know" (?/p) answer to be the third relevant response to a yes/no question. The illegitimate step from doubt to negation $(? / p \rightarrow-/ p)$ constitutes "the 'ordinary' argumentum ad ignorantiam" and plays, so to speak, an auxiliary role in committing the false dilemma as described in the quote above (van Eemeren \& Grootendorst, 1992, p. 190). But for them the crux of the false dilemma lies in confusing contrary standpoints for contradictory ones. This is crucial here, since contrary standpoints cannot but be responses to Wh-questions such as, for instance, "Where can we still see a glimmer of hope in that terrible genocide in Kosovo?" discussed in van Eemeren et al., 2007, p. 61). Accordingly, pragma-dialectics does allow for discussions over such questions which lead to the adoption of contrary standpoints by the protagonist and antagonist. This happens in a "qualitatively multiple dispute" arising when the second speaker "takes up an alternative standpoint [...] [that], viewed dialectically, implies a standpoint that is opposite to" the first speaker's standpoint (van Eemeren et al., 2007, pp. 26-27). Then, however, if 


\section{Argumentative Polylogues: Beyond Dialectical Understanding of Fallacies}

a dispute proceeds between only two arguers discussing only two contraries out of "multiple" possibilities, it is nothing short of a false dilemma. If it involves multiple parties with multiple contrary positions, it is a polylogue. (I hope it's not a false dilemma.)

27 See also Blair (1998). A famous account of inner dialectics is given by Plato:

[Thought amounts to] the talk which the soul has with itself about any subjects which it considers. [... T] he soul [...] when it thinks, is merely conversing with itself, asking itself questions and answering, affirming and denying. [...] I define forming opinion as talking and opinion as talk which has been held, not with someone else, not yet aloud, but in silence with oneself. (Plato, Theaetetus, 189e-190a; see The Sophist, 263e-264b)

28 Hamblin is quite clear about this: "Since we are concerned mainly with two-person dialogues we can dispense with the phenomenon of discriminatory direction of locutions to one person rather than another, and assume that all locutions are directed to the other participant." (1970, p. 257).

29 See above, sec. 2.1 and n. 6 for a discussion of various types of questions.

30 Note that a false dilemma may be "justified" by other fallacies violating rule 1 such as ad hominem: "We will only discuss these two options since all other alternatives are stupid beyond imagination."

31 Ad ignorantiam in the case of yes/no questions can be understood on the grounds of tri-valued logic as an illegitimate step from a doubt about a proposition ("I'm not sure if God exists") to its negation ("so it doesn't exist"). See above n. 26.

\section{R E F E R E N C E S}

Aikin, S. F., \& Casey, J. (2011). Straw men, weak men, and hollow men. Argumentation, 25(1), 87-105.

Aristotle. (1997). Topics. Books I and VIII (transl., intr. and notes by R. Smith). Oxford: Clarendon Press.

Barth, E. M., \& Krabbe, E. C. W. (1982). From axiom to dialogue: A philosophical study of logics and argumentation. Berlin: Walter de Gruyter.

Benthem, J. van. (2009). Foreword. In I. Rahwan \& G. R. Simari (Eds.), Argumentation in Artificial Intelligence (pp. vii-viii). Dordrecht: Springer.

Blair, J. A. (1998). The limits of the dialogue model of argument. Argumentation, 12(3), 325-339.

Botting, D. (2011). Can 'big' questions be begged? Argumentation, 25(1), 23-36.

Bruxelles, S., \& Kerbrat-Orecchioni, C. (2004). Coalitions in polylogues. Journal of Pragmatics, 36(1), 75-113.

Canary, D. J., Brossmann, B. G., \& Seibold, D. R. (1987). Argument structures in decision-making groups. Southern Speech Communication Journal, 53(1), $18-37$.

Chen, H. (2010). The concept of the "polylogue" and the question of "intercultural" identity. Intercultural Communication Studies, 19(3), 54-64.

Clark, H. H., \& Carlson, T. B. (1982). Hearers and speech acts. Language, 58(2), $332-373$. 


\section{Marcin Lewiński}

Copi, I. M., \& Cohen, C. (1990). Introduction to logic. 8th Ed. New York: Macmillan.

Dascal, M. (2008). Dichotomies and types of debate. In F. H. van Eemeren \& B. Garssen (Eds.), Controversy and confrontation: Relating controversy analysis with argumentation theory (pp. 27-49). Amsterdam: John Benjamins.

Eemeren, F. H. van. (2010). Strategic maneuvering in argumentative discourse: Extending the pragma-dialectical theory of argumentation. Amsterdam: John Benjamins.

Eemeren, F. H. van, \& Grootendorst, R. (1984). Speech acts in argumentative discussions: A theoretical model for the analysis of discussions directed towards solving conflicts of opinion. Dordrecht: Foris.

Eemeren, F. H. van, \& Grootendorst, R. (1992). Argumentation, communication, and fallacies: A pragma-dialectical perspective. Hillsdale, NJ: Lawrence Erlbaum.

Eemeren, F. H. van, \& Grootendorst, R. (2004). A systematic theory of argumentation. Cambridge: Cambridge University Press.

Eemeren, F. H. van, Houtlosser, P., \& Snoeck Henkemans, A. F. (2007). Argumentative indicators in discourse: A pragma-dialectical study. Dordrecht: Springer.

Fairclough, I., \& Fairclough, N. (2012). Political discourse analysis: A method for advanced students. London: Routledge.

Fogelin, R. J. (1985). The logic of deep disagreements. Informal Logic, 7(1), 1-8.

Goffman, E. (1981). Forms of talk. Oxford: Blackwell.

Goodwin, C., \& Goodwin, M. H. (1990). Interstitial argument. In A. D. Grimshaw (Ed.), Conflict talk: Sociolinguistic investigations of arguments in conversations (pp. 85-117). Cambridge: Cambridge University Press.

Hamblin, C. L. (1970). Fallacies. London: Methuen.

Haviland, J. B. (1986). 'Con Buenos Chiles': Talk, targets and teasing in Zincantán. Text, 6(3), 249-282.

Hymes, D. (1972). Models of the interaction of language and social life. In J. J. Gumperz \& D. Hymes (Eds.), Directions in sociolinguistics: The ethnography of communication (pp. 35-71). New York: Holt, Rinehart and Winston.

Jacquette, D. (2007). Two sides of any issue. Argumentation, 21(2), 115-127.

Johnson, R. (2000). Manifest rationality. Mahwah, NJ: Lawrence Erlbaum.

Kerbrat-Orecchioni, C. (1997). A multilevel approach in the study of talk-ininteraction. Pragmatics, $7(1), 1-20$.

Kerbrat-Orecchioni, C. (2004). Introducing polylogue. Journal of Pragmatics, $36(1), 1-24$.

Krabbe, E. C. W. (2006). Logic and games. In P. Houtlosser \& M. A. van Rees (Eds.), Considering pragma-dialectics (pp. 185-198). Mahwah: Lawrence Erlbaum Associates. 
Lennox, J. G. (1994). Aristotelian problems. Ancient Philosophy, 14, 53-77.

Levinson, S. C. (1988). Putting linguistics on a proper footing: Explorations in Goffman's concepts of participation. In: P. Drew \& A. Wootton (Eds.), Erving Goffman: Exploring the interaction order (pp. 161-227). Cambridge, MA: Polity Press.

Lewiński, M. (2010). Collective argumentative criticism in informal online discussion forums. Argumentation and Advocacy, 47(2), 86-105.

Lewiński, M. (2011). Towards a critique-friendly approach to the straw man fallacy evaluation. Argumentation, 25(4), 469-497.

Lewiński, M. (2013). Debating multiple positions in multi-party online deliberation: Sides, positions, and cases. Journal of Argumentation in Context, 2(1), 151177.

Lewiński, M., \& Aakhus, M. (forth.). Argumentative polylogues in a dialectical framework: A methodological inquiry. Argumentation, online first: http://dx.doi.org/10.1007/s10503-013-9307-x.

Lewiński, M., \& Mohammed, D. (2012). Disagreeing on the same side of the barricade: Argumentation in multi-party political discussions during the Arab Spring. Paper presented at the 4th International conference Critical Approaches to Discourse Analysis Across Disciplines (CADAAD), University of Minho, Braga, Portugal, July 4-6.

Maynard, D. W. (1986). Offering and soliciting collaboration in multi-party disputes among children (and other humans). Human Studies, 9, 261-285.

Perelman, Ch., \& Olbrechts-Tyteca, L. (1969). The new rhetoric: A treatise on argumentation (transl. by J. Wilkinson \& P. Weaver. Notre Dame: University of Notre Dame Press. (Original work published 1958.)

Plato. (1921). Theaetetus. Sophist (transl. by H. N. Fowler). Loeb Classical Library, 123. Cambridge, MA: Harvard University Press.

Prakken, H. (2009). Models of persuasion dialogue. In I. Rahwan \& G. R. Simari (Eds.), Argumentation in Artificial Intelligence (pp. 281-300). Dordrecht: Springer.

Quine, W. V. (1951). Two dogmas of empiricism. The Philosophical Review, 60(1), $20-43$.

Quine, W. V., \& Ullian, J. S. (1970). The web of belief. New York: McGraw-Hill.

Searle, J. R. (1969). Speech acts: An essay in the philosophy of language. Cambridge: Cambridge University Press.

Searle, J. R. (1992). Conversation. In J. R. Searle et al. (Eds.) (On) Searle on conversation (pp. 7-29). Amsterdam: John Benjamins.

Spranzi, M. (2011). The art of dialectic between dialogue and rhetoric: The Aristotelian tradition. Amsterdam: John Benjamins.

Sylvan, R. (1985). Introducing polylogue theory. Philosophica, 35(1), 89-112.

Talisse, R., \& Aikin, S.F. (2006). Two forms of the straw man. Argumentation, 20(3), 345-352. 


\section{Marcin Lewiński}

Tomić, T. (2013). False dilemma: A systematic exposition. Argumentation, 27(4), 347-368.

Traverso, V. (2004). Interlocutive 'crowding' and 'splitting' in polylogues: The case of a researchers' meeting. Journal of Pragmatics, 36(1), 53-74.

Walton, D. N. (1992). Nonfallacious arguments from ignorance. American Philosophical Quarterly, 29(4), 381-387.

Walton, D. N. (2004). Relevance in argumentation. Mahwah, NJ: Lawrence Erlbaum.

Walton, D. N., \& Krabbe, E. C. W. (1995). Commitment in dialogue: Basic concepts of interpersonal reasoning. Albany: State University of New York Press.

Wimmer, F.M. (1998). Introduction. In Special issue on intercultural philosophy. Topoi, 17(1), 1-13.

Wimmer, F.M. (2007). Cultural centrisms and intercultural polylogues in philosophy. International Review of Information Ethics, 7(9), 1-8.

Wittgenstein, L. (2001). Philosophical investigations. $3^{\text {rd }}$ ed. G.E.M. Anscombe \& R. Rhees (eds.), (transl. by G.E.M. Anscombe). Oxford: Blackwell.

Zarefsky, D. (2008). Strategic maneuvering in political argumentation. Argumentation, 22(3), 317-330. 